Article

\title{
Reversible Heat Pump Coupled with Ground Ice Storage for Annual Air Conditioning: An Energy Analysis
}

\author{
Simone Mancin and Marco Noro *(1) \\ Department of Management and Engineering, University of Padova, 36100 Vicenza, Italy; \\ simone.mancin@unipd.it \\ * Correspondence: marco.noro@unipd.it
}

Received: 28 October 2020; Accepted: 23 November 2020; Published: 24 November 2020

\begin{abstract}
During annual operation, a heat pump produces both heating and cooling effects, so it would be of great advantage to store one of the two to be then used when it is necessary. To do this, a seasonal energy storage is necessary. This paper presents results relative to the use of a ground ice thermal energy storage (I-TES) integrated with a reversible heat pump for annual air conditioning. The energy analysis is based on heating and cooling loads for a residential building located in Milan. In particular, the focus is on the most important parameters affecting the performance of both the whole system and the Ice Tank, which is the position and the thickness of the insulation layers and the shape of the ice tank. A biannual simulation of the system allows for a full description of the ice tank behavior during the charging and discharging processes. The main objective of the study is to suggest a first tentative procedure to design the I-TES integrated system with the best energy performance.
\end{abstract}

Keywords: ground source heat pump; heat pump; ice thermal energy storage; ice tank

\section{Introduction}

In temperate climates, reversible heat pumps usually provide heating in winter and cooling in summer. During operation, a heat pump produces both effects; thus, it would be of great advantage to store one of the two to be then used when it is necessary. For example, the heat released at the condenser could be stored in summer when producing cooling, and the cold produced at the evaporator could be stored in winter when producing heating. As a matter of fact, the problem is to provide a storage of sufficient size to store/release the large quantities of energy available during a whole heating or cooling period.

The combination of ground source heat pumps (GSHP) and thermal energy storage (TES) systems can be a viable solution in cases with a heating and cooling imbalance [1-4]. TES systems allow a more efficient exploitation and utilization of energy resources because of an improved matching between the energy supply and the demand. Phase change materials (PCM), water, soil, solar thermal collectors and ice storage tanks are the main TES technologies integrated with GSHP systems [5,6].

In recent years, several studies have dealt with the enhancement of the performance of GSHP systems, improving the accuracy of the models and design methods. Luo et al. [7] proposed an original model for U-tube ground heat exchangers (GHE); they studied the effect of ground surface flux of the techniques of treating non-uniform pipe wall temperatures and heat flux. In [8], the temperature distribution of the ground source of heat pumps varying during the time was presented for a long-term operation of a system of 25 double U-tube borehole heat exchangers. Lazzarin and Noro [9] presented a dynamic simulation of a photovoltaic/thermal (PVT) dual source reversible heat pump. In this case, ground and PVT were used as source/sink, with the latter also driving the heat pump compressor. A very high energy efficiency configuration and control logic of the plant was set up by means of dynamic simulation. 
At the same time, the monitoring of GSHP plants is very important. Spitler and Gehlin [10] provided long-term measured system performance data of the GSHP system installed at the new student center at Stockholm University in Sweden. They described the interactions between the different system components and how they affect its performance, also giving useful suggestions on how the design may be ameliorated. The authors of the present paper worked on this subject in the recent past: in [11], bad operation of the plant and particularly of the multisource heat pumps (outdoor air, ground, solar radiation and ventilation heat recovery as heat sources) was found out by a long-period analysis. In [12], the results of the monitoring of the first years of operation of an underground water source electrical compression reversible heat pump set up on a historical building in Vicenza (Italy) were presented. In both cases, the identification of inefficient operation of the plant was realized by a careful analysis of energy and operation data.

Moreover, theoretical analyses and experimental studies on TES systems are largely studied in literature. Sanner et al. [13] reported a review of an underground thermal energy storage (UTES) in Europe. Yang et al. [14] analyzed GSHPs' current status in China, limiting the study to an integrated soil cold storage and GSHP system. Zhai et al. [15] summarized the main integrated approaches of GSHP systems integrated with TES technologies, but they concluded that ground heat exchangers were the most diffused ones.

As a matter of fact, combining a GSHP with a TES appear to be the suitable solution to face the needs of a building. Considering the seasonal thermal energy storage, PCMs are very interesting as they can store huge amounts of thermal energy. The authors already proved the energy viability of a hybrid water-PCM TES by an annual simulation of a multi-source absorption reversible heat pump plant (solar and ground) installed in a building in northern Italy [16]. The cost of most PCMs can be a disincentive to the use of this kind of solution, as well as their poor thermal conductivity, even if the latter aspect can be overcome [17].

Ground water can be a viable solution both technically and economically to be integrated with a reversible heat pump for annual air conditioning. For example, Zhang et al. [18] studied the annual performance of a ground water pond-coupled heat pump system in Changiiang Valley in China, varying the thickness of the insulating cover, the volume of the water pond and the type of soil.

Ice storage is another interesting solution. In [19], a building complex in Oslo, Norway, was set up by a heating and cooling system with heat pumps, solar thermal collectors, ice thermal energy storage and borehole thermal energy storage. More specifically, ground ice storage can be useful for coupling with HPs in unbalanced thermal loads buildings; during winter, the reversible heat pump takes heat from the I-TES (forming ice), while during summer, it is possible to liquefy the ice for free cooling (even if it should be considered that some energy and related costs are spent in the long term in order to store this potential). This solution could lower the nominal cooling power of the chiller and save energy in cooling season, with obvious advantages from the energy savings standpoint. D'Ingeo [20] analyzed the basic design principles and a case study of a ground ice storage coupled to a gas-fired absorption reversible heat pump for annual climatization of a commercial building.

Moreover, many theoretical studies have recently been implemented on this topic. In [21], an ice storage buried in the ground was modelled, and one year of operation of a pilot plant allowed its validation. Such a model was used for transient yearly simulations for the cities of Strasbourg [22] and Zurich [23] by analyzing the influence of different control logic, areas and types of solar collectors and volumes of ice storages on system performance. As a matter of fact, many problems must be faced as regards the size of the storage, which must be compared with the building heating and cooling demands, also taking into account the required insulation of the storage and considering, when it is located underground, the different types of soil.

The various aspects of a ground ice storage coupled with a reversible heat pump system are considered in this paper, with a suitable analysis with an annual dynamic simulation by Trnsys 17 [24] of a reference residential building located in Milan. The best energy performance of the system analyzed here can be reached in continental climates, such as in Milan, with high or not-so-low seasonal 
ranges of outdoor temperatures, because of high production of ice at the evaporator during the cold heating season that can be suitably used during the hot and/or humid summer. A specific type for buried vertically stratified thermal energy storage (type 343) is used in this study. To the best of the authors' knowledge, only one study is present in literature on using Trnsys and type 343 to simulate such a system, but it is focused on the presentation of a Trnsys-based stand-alone tool to enable users to analyze different predefined solar heat pump concepts [25]. As the main novelty of this study, results in terms of ice volume fraction inside the storage and primary energy consumptions of the heat pump system are presented. These can give useful advice for the first design of a system to be further investigated in future development of the work.

The rest of the paper is organized in the following sections: Section 2 reports on the reference building and heating, ventilation and air conditioning (HVAC) plant model and simulation with particular focus on the ice tank (IT); Section 3 reports the main results of the simulation as a comparison between the different alternatives based on both primary energy consumption and the ice volume fraction. An optimization of the volume of ice thermal energy storage (I-TES) is presented as well. Finally, in Section 4, some remarks and conclusions are reported.

\section{Model Development}

\subsection{Reference Building Simulation}

As a possible application, a residential building in a typical north Italian climate (Milan, $45.5^{\circ} \mathrm{N}$ ) was considered. According to Koppen classification (www.wikipedia.it), Milan's climate is Cfb, which is temperate and humid in all seasons and has a climate with a hot summer-the hottest month has a mean temperature lower than $22{ }^{\circ} \mathrm{C}$. The volume of the building is $350 \mathrm{~m}^{3}$ with a plan area of $135 \mathrm{~m}^{2}$. The simulated gains are correlated to a presence of a family of four people.

In winter, the temperature set point during the day is $20^{\circ} \mathrm{C}$, with an attenuation to $16{ }^{\circ} \mathrm{C}$ with the presence of no people (for example, in the sleeping area during the daytime). In summer, the temperature set point during the day is $26^{\circ} \mathrm{C}$, up to $28^{\circ} \mathrm{C}$ following the previous schedule. The air relative humidity can also vary between $55 \%$ and $75 \%$. The internal devices of the HVAC system are fan-coils that are supplied with hot water at $50{ }^{\circ} \mathrm{C}$ in winter. In summer, they receive chilled water at $7{ }^{\circ} \mathrm{C}$ so that latent loads can be faced. Heating and cooling energy needs, calculated by Trnsys, are reported in Figure 1.

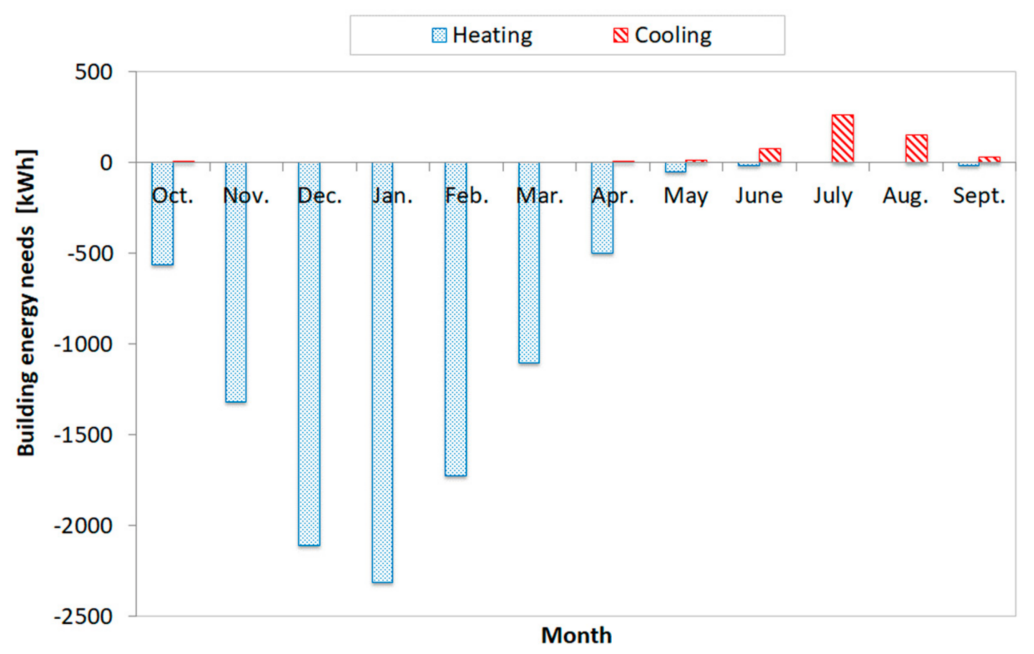

Figure 1. Simulated monthly energy needs of the building. 


\subsection{Trnsys Model}

A Trnsys model of the system was developed to simulate the behavior of the I-TES integrated with an HP for civil house heating and cooling. Figure 2 reports a simplified schematic of the Trnsys model. The main components are the IT, the HP, the GHE, the Auxiliary Heater (Aux. H), the pumps, the Cold and Hot Tanks and the LOADS.

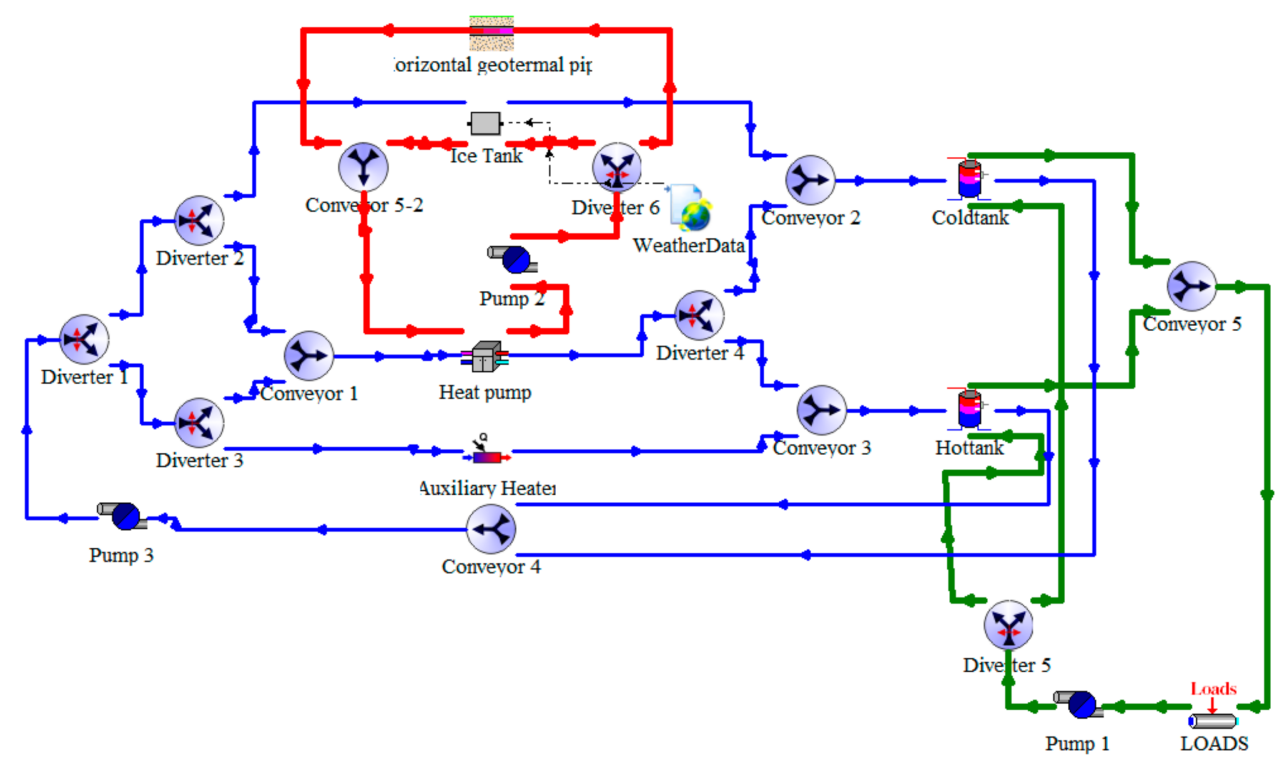

Figure 2. Schematic of the Trnsys model.

The model is composed of three water circuits (Figure 2)

- Primary circuit (blue): Pump 3 is ON when there are cooling loads and the average temperature of the Cold Tank is greater than $7^{\circ} \mathrm{C}$ or when there are heating loads and the average temperature of the Hot Tank is lower than $35^{\circ} \mathrm{C}$. The Auxiliary Heater simulates an integration boiler (thermal efficiency 0.9 ) that operates when heating load is greater than HP capacity in the operating conditions of that time step.

- Secondary circuit (red): Pump 2 is ON when HP is ON. This happens when heating load is lower than HP capacity (in heating mode) or when cooling load cannot be satisfied by the ice contained in the storage (in cooling mode). In the first case, the water in the storage freezes as it is the heat source of the HP; in the second case, the ice in the storage melts as it is a free cooling source.

- Tertiary circuit (green): Pump 1 is ON when there are some thermal loads (supply water temperature is 7 and $40{ }^{\circ} \mathrm{C}$ in cooling and heating operation, respectively).

Three different cases can occur-the energy stored in the IT as ice might be enough or more/less than enough. If the energy stored is more or enough, the heat pump will not operate and all the cooling load will be satisfied by the working fluid, which is cooled by liquefying the ice contained into the IT (free cooling). Otherwise, when the stored energy is not enough, the reversible heat pump will operate using a geothermal heat exchanger to reject the heat load (GHE in Figure 2). This solution was selected in order to not heat the water contained in the IT, which will delay the ice growth in the following heating season.

The rated characteristics of the main equipment are:

- $\quad$ Reversible HP: heating power $9 \mathrm{~kW}$ (COP 3.45), cooling power $8 \mathrm{~kW}$ (EER 3.9), refrigerant R32;

- Tanks capacity: Cold Tank, 300 L; Hot Tank, 1000 L;

- $\quad$ GHE: 60-m length; internal diameter (ID) 23-mm polyethylene (PE) tubes; depth, $3 \mathrm{~m}$. 
The time-step of the simulation was $15 \mathrm{~min}$. Two consecutive years were simulated, and the 1 October-30 September period was considered in the following analysis.

\subsubsection{IT Type}

The IT-type 343-considers an underground vertically stratified storage, which can be cylindrical or conical with circular bases. According to Figure 3a, the storage can be subdivided in different elements. Two different circuits pass through each element: the charging one is connected to the HP and it is used during the heating operation of the system, while the second one is connected to the load and it allows for the use of the ice during the cooling operation. The type permits to set an insulation layer on the top, while it does not allow for a direct selection of the insulation for both the side and the bottom surfaces. The storage materials and the soil are defined by their thermophysical properties. The heat transfer and absorption coefficients at the ground surface can be set.

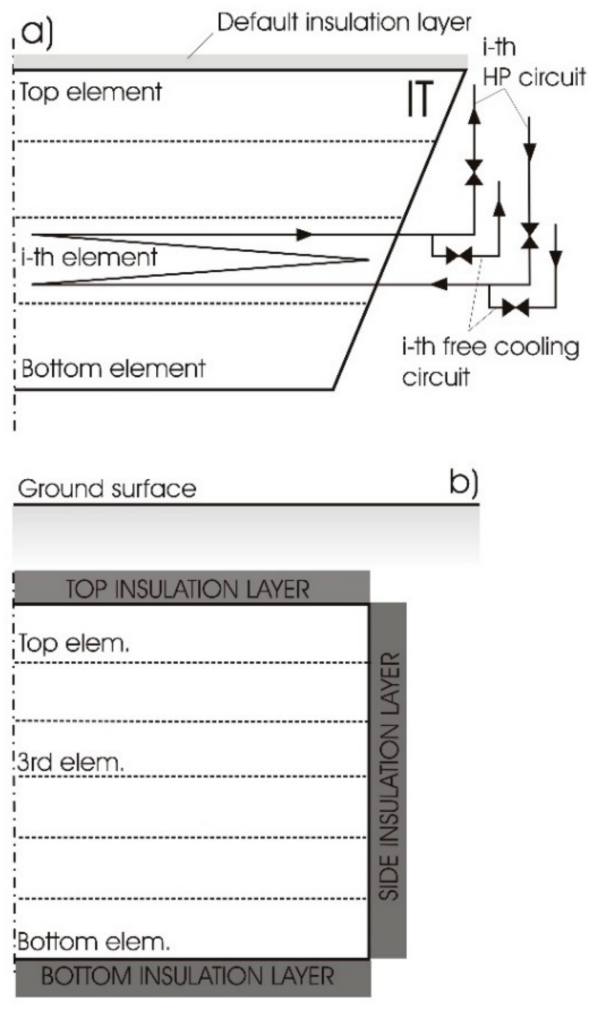

Figure 3. Ice tank (IT) schemes: (a) general; (b) case study.

The volume of the storage should be designed considering the total amount of energy which could be exchanged by the HP evaporator with the heat source during the heating season (Equation (1)). In the selected case, the volume of the IT was estimated to be equal to $58.8 \mathrm{~m}^{3}$, subdivided in six ( $0.5 \mathrm{~m}$ high) elements:

$$
V_{I T}=\frac{E_{\text {evap }, H P} \cdot 3600}{\left(\rho_{\mathrm{H}_{2} \mathrm{O}} \cdot c_{\mathrm{H}_{2} \mathrm{O}} \cdot \Delta T_{\mathrm{H}_{2} \mathrm{O}}+\rho_{\text {ice }} \cdot r_{\text {ice }}\right)}=\frac{5474 \cdot 3600}{(1000 \cdot 4.187 \cdot(7-0)+917 \cdot 333.5)}=58.8 \mathrm{~m}^{3}
$$

where:

- $\quad V_{I T}=$ volume of the IT;

- $E_{\text {evap,HP}}=$ energy exchanged by the HP evaporator during heating operation as a result of the simulations $(\mathrm{kWh})$;

- $3600=$ unit conversion factor $\left(\mathrm{kJ} \mathrm{kWh}^{-1}\right)$; 
- $\rho_{\mathrm{H} 2 \mathrm{O}}=$ liquid water density $\left(\mathrm{kg} \mathrm{m}^{-3}\right)$;

- $\quad c_{\mathrm{H} 2 \mathrm{O}}=$ liquid water specific heat $\left(\mathrm{kJ} \mathrm{kg}^{-1} \mathrm{~K}^{-1}\right)$;

- $\Delta T_{\mathrm{H} 2 \mathrm{O}}=$ temperature difference between the minimum for cooling operation and freezing (K);

- $\quad \rho_{\text {ice }}=$ solid water density $\left(\mathrm{kg} \mathrm{m}^{-3}\right)$;

- $\quad r_{i c e}=$ solidification water latent heat $\left(\mathrm{kJ} \mathrm{kg}^{-1}\right)$.

The cylindrical shape was considered with a base diameter equal to $5 \mathrm{~m}$ while the height was $3 \mathrm{~m}$; the structure was made of a $0.2-\mathrm{m}$ thick concrete walls. The IT was located $2 \mathrm{~m}$ under the ground surface. Polyethylene (PE) was considered as insulation material. In each element, a 30-m long, 16-mm ID, PE tube was located to exchange the requested amount of heat during the operation. As described before, the type permits to set a customized insulation layer on the top surface of the tank but it does not allow the same operation on both the side and bottom surfaces. The problem can be overcome by a proper selection of the overall heat transfer coefficient of these walls. In this way, different insulation configurations can be easily set and simulated.

Figure $3 b$ shows the different possible insulation configurations, while Table 1 lists the studied cases. In particular, the effects of both the position and the thickness of the insulation layers were simulated. Furthermore, based on the best solution, different IT shapes and volumes were analyzed. For the sake of clarity, it is worth stressing that when the storage volume was reduced (for example, TOP_5_CONE), the length of the pipes located in each element was accordingly redefined.

Table 1. IT configurations.

\begin{tabular}{cccccc}
\hline Type & Shape & Top $\mathbf{( c m )}$ & Side $\mathbf{( c m )}$ & Bottom $\mathbf{( c m )}$ & Volume $\left.\mathbf{( m}^{\mathbf{3}}\right)$ \\
\hline NO_INS & Cylindrical & - & - & - & 58.8 \\
TOP_5 & Cylindrical & 5 & - & - & 58.8 \\
TOP_10 & Cylindrical & 10 & - & - & 58.8 \\
TOP_BOT_5 & Cylindrical & 5 & - & 5 & 58.8 \\
TOP_BOT_10 & Cylindrical & 10 & - & 10 & 58.8 \\
TOP_SIDE_5 & Cylindrical & 5 & 5 & - & 58.8 \\
TOP_SIDE_10 & Cylindrical & 10 & 10 & - & 58.8 \\
ALL_INS_5 & Cylindrical & 5 & 5 & 5 & 58.8 \\
ALL_INS_10 & Cylindrical & 10 & 10 & 10 & 58.8 \\
TOP_5_CONE & Cone & 5 & - & - & 44.9 \\
TOP_5_CYL_1 & Cylindrical & 5 & - & - & 44.6 \\
TOP_5_CYL_2 & Cylindrical & 5 & - & - & 37.7 \\
\hline
\end{tabular}

\subsubsection{Reference System}

A reference system, named NO_IT, was implemented to quantify the energy savings achievable with the use of I-TES. A chiller and an off-the-shelf heater were selected to satisfy the cooling and heating loads, respectively. The overall primary energy consumption was estimated to be $16,614 \mathrm{kWh}$ (around $1870 \mathrm{kWh}$ for cooling) on the basis of the Trnsys simulation of the heat loads provided in Figure 1.

\section{Results}

In this section, the main results of the simulation are presented. Firstly, a comparison between the different alternatives based on primary energy consumption is reported. Successively, a few more considerations are reported based on a comparison focused on the ice volume fraction; finally, an optimization of the volume of the I-TES is presented.

\subsection{Primary Energy Consumption Comparison}

The analysis involved the simulations conducted keeping the storage volume constant to $58.8 \mathrm{~m}^{3}$. These cases allow for highlighting the effects of the insulation layers on the performance of the IT 
and, consequently, the I-TES integrated system. According to Table 1, nine cases were investigated by varying both the thickness and the position of the insulations layer/s.

Figure 4 reports the comparison among the nine case studies by plotting their overall primary energy consumption, considering a non-renewable primary factor $f_{p, \text { nren }}=1.95$ according to Italian standard DM 26/06/2015 for electricity consumed by the HP and the pumps (efficiency $=51.3 \%$ ) and 1.1 for the auxiliary heater (efficiency $=90 \%$ ).

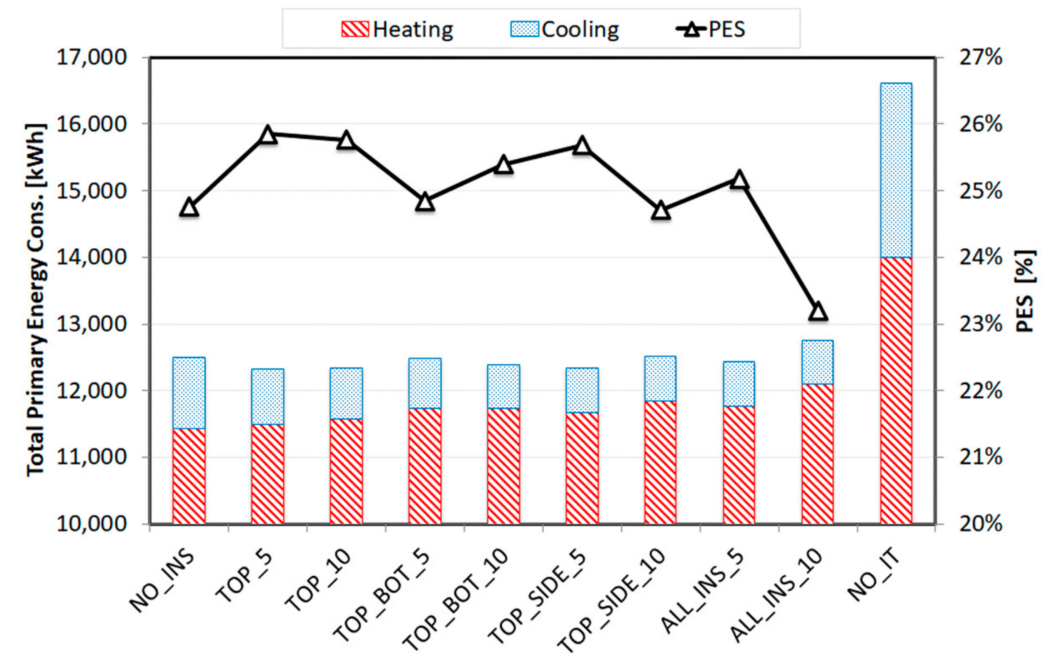

Figure 4. Effect of the insulation layout on the annual system performance: non-renewable primary energy consumption (left axis) and primary energy saving (right axis).

As it clearly appears, the use of I-TES permits a remarkable reduction in the primary energy consumption as compared to the reference case (NO_IT). The best performance is achieved by the TOP_5 case with $25.8 \%$ primary energy saving (PES). This IT uses just a $5-\mathrm{cm}$ thick layer of insulation located on the top wall of the IT. The other solutions imply the use of a greater amount of insulation material with lower primary energy savings, between 23.2\% (ALL_INS_10) and 25\%.

In order to explain the results, a deep analysis of the IT must be addressed. The IT is cooled down during the winter, being the cold sink of the heat pump. A certain amount of ice is formed in each layer of the IT as a function of the position of the element in the storage (see Figure 3). The first and the sixth elements are the most penalized because they have the largest heat transfer areas in contact with the soil. By varying the overall insulation of the IT, it is possible to control the amount of energy stored (transformed into ice) and the amount dissipated through the boundaries. The formed ice is then used during the summer to satisfy the requested cooling loads.

It is interesting to point out that when the stored energy is greater than the overall cooling energy demand, a certain amount of ice can remain at the end of the cooling season, which will affect the behavior of the I-TES in the following winter.

Figure 5 explains these concepts; in particular, it reports the energy analysis of the IT during the second year of simulation. The diagram shows the values of the stored and the lost energy, the cooling contribution of the IT to the cooling load and, on the second $y$-axis, the remaining ice at the end of September of the second year. At a glance, it appears that the stored energy during the heating season is almost the same in all the cases. This can be explained by considering the fact that the IT is the only heat sink for the reversible heat pump during the heating operation. The amount of heat lost to the soil changes as a function of the degree of insulation of the storage. As expected, minimal energy losses are obtained when a $10-\mathrm{cm}$ thick insulation layer covers all the surfaces. In this case, ALL_INS_10, more than 50\% of the ice remains after the second cooling season (Figure 5), meaning that in the following winter season, the volume of the IT will not be enough anymore to sustain the ice production. 


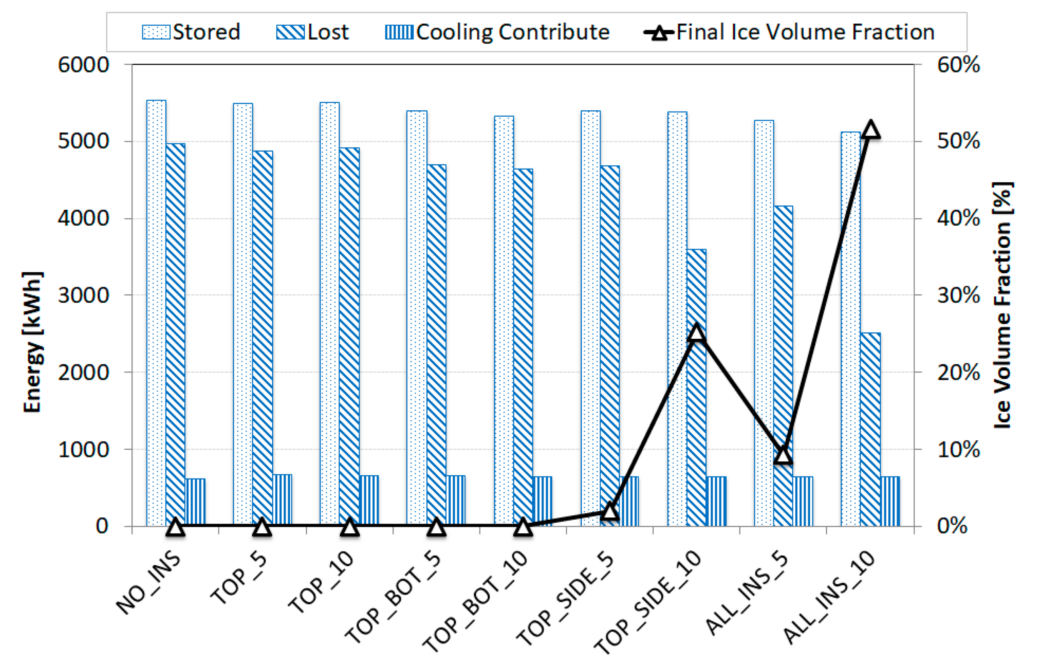

Figure 5. Energy analysis of the IT (second year of simulation).

By comparing Figures 4 and 5, it clearly appears that the minimum primary energy consumptions, i.e., the maximum primary energy savings, are achieved by the best trade-off between the stored energy during the winter and the sum of the energy lost and the cooling load. When a large volume fraction of the IT is frozen, the HP performance decreases because of the lower mean evaporation temperature; this can explain why the primary energy consumptions are higher for the all-insulated cases as compared to the other cases.

This fact is confirmed by the results plotted in Figure 6, the primary energy consumption for three different cases: NO_INS, ALL_INS_10 and ALL_INS_5. The non-insulated case exhibits the lowest energy consumptions during the heating season, but then, during the cooling season, the produced ice is not sufficient to satisfy the cooling load, causing the HP to operate using the geothermal heat exchanger.

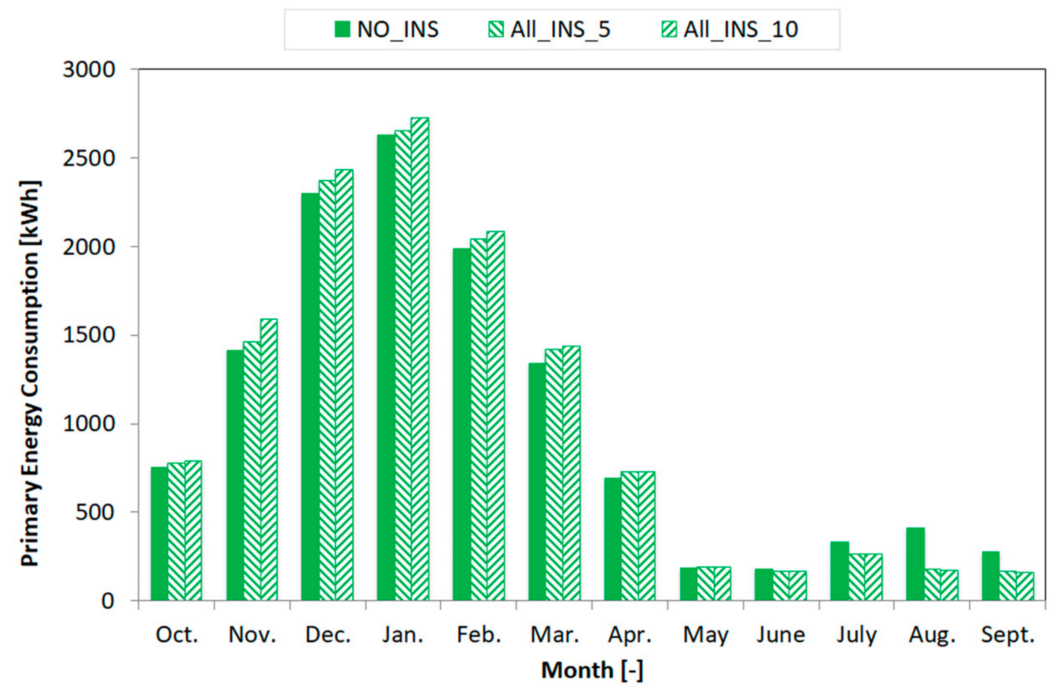

Figure 6. Comparison of all the insulated cases.

\subsection{Yearly Ice Volume Fraction Analysis}

Figure 7 shows the ice volume fraction of the IT during the two-year simulation for the $10-\mathrm{cm}$ thick insulation layer cases. As described before, when all the surfaces are insulated, more than $50 \%$ of the storage volume is frozen at the end of the second year, leading to the impossibility of the use of the whole IT volume during the following winter. 


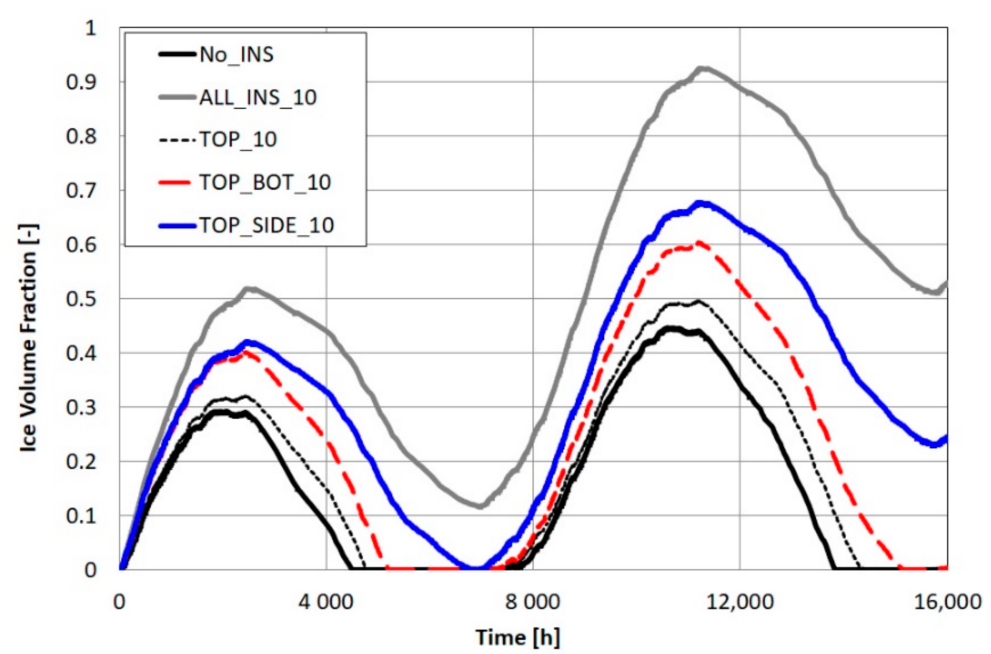

Figure 7. Ice volume fraction over the two-year simulation with cases with $10-\mathrm{cm}$ thick insulation.

The same results for 5-cm thick insulation layers are plotted in Figure 8; it is worth underlining that in the TOP_ 5 case, which exhibits the lowest primary energy consumptions, only less than $50 \%$ of the storage volume is frozen during the second year, but this volume is enough to satisfy the cooling loads without any contribution of the HP.

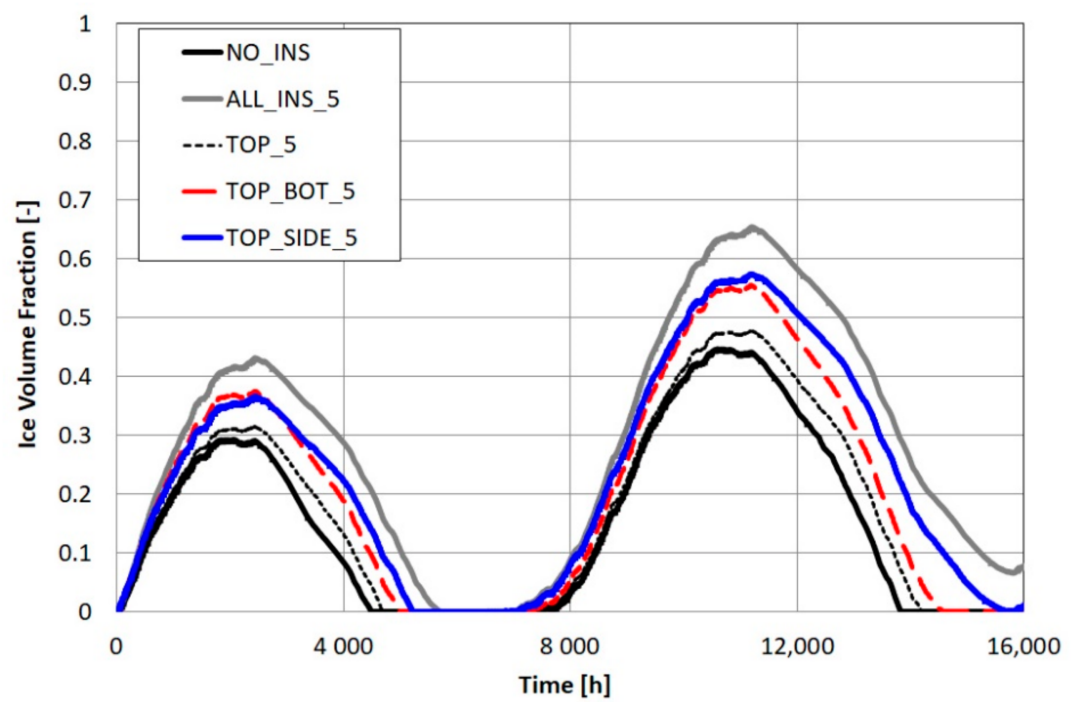

Figure 8. Ice volume fraction over the two-year simulation with cases with 5-cm thick insulation.

Figure 8 shows that a non-negligible amount of ice can also be found in the ALL_INS_5, even if this quantity would not jeopardize the energy storing in the following heating season. In order to analyze the IT behavior during the charging and discharging processes in more detail, it might be interesting to visualize the ice volume fraction throughout the elements.

In particular, Figure 9 reports two diagrams relative to the 3rd layer with 5- and 10-cm thick insulation layers. The diagrams clearly show the effect of the different insulation thicknesses on the volume fraction of ice formed during the storage charge. In the ALL_INS_10 case, the 3rd element (and also the 4th one) is completely frozen, and after the second cooling season, only around 35\% of the ice is liquefied. Similar results can also be highlighted for the TOP_SIDE_10 case. In Figure 9b, similar behavior is exhibited by the 3rd element of the ALL_INS_5 case, which, at the end of the second year, has some $20 \%$ of its volume not liquefied. 

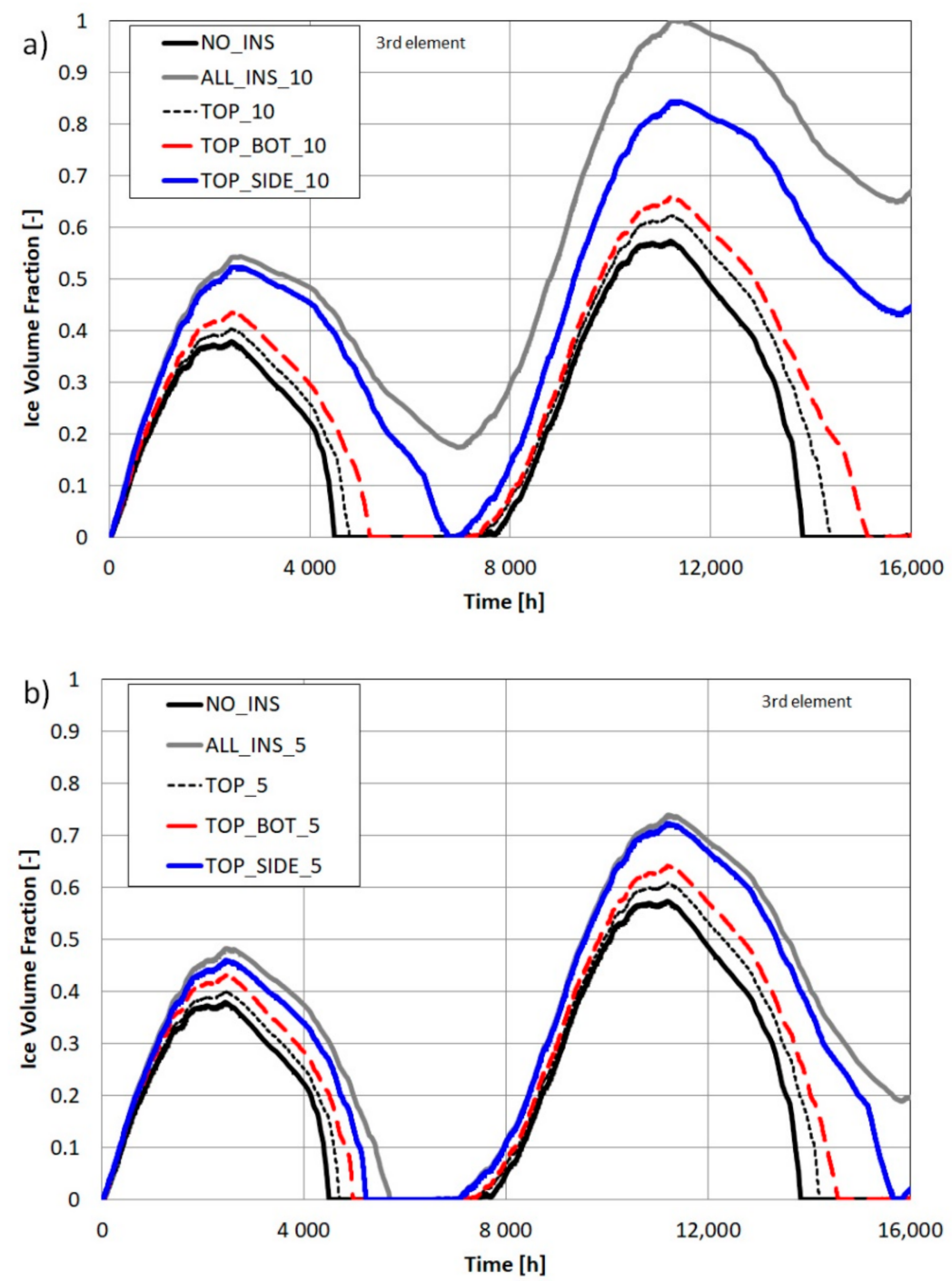

Figure 9. Ice volume fraction of the 3rd element of the IT: (a) 10-cm cases; (b) 5-cm cases.

The analysis can be extended to the bottom (6th element) of the IT; Figure 10 reports the same diagrams for 10- and 5-cm cases.

The ALL_INS_10 case remains the most penalized; furthermore, it clearly appears that the bottom element of the IT is the one that loses the highest amount of energy due to having the largest heat transfer area.

Nevertheless, even if the TOP_5 and the NO_INS cases exhibit almost the same amount of ice formed in the bottom element, it seems that the contribution of this element to the energy lost through the soil is very important to counterbalance the large amount of energy that has to be stored in the IT in relation with the relatively low cooling demands. The TOP_ 5 case seems to be the best trade-off between the heating and cooling demands integrated with the I-TES behavior.

\subsection{I-TES Optimization}

From the analysis of the previous results, it was demonstrated that just a 5-cm thick insulation layer located on the top wall surface of the IT is sufficient to balance its bi-annual performance when the storage volume is designed on the basis of the total amount of energy to be absorbed by the evaporator side of the HP during the heating season. 

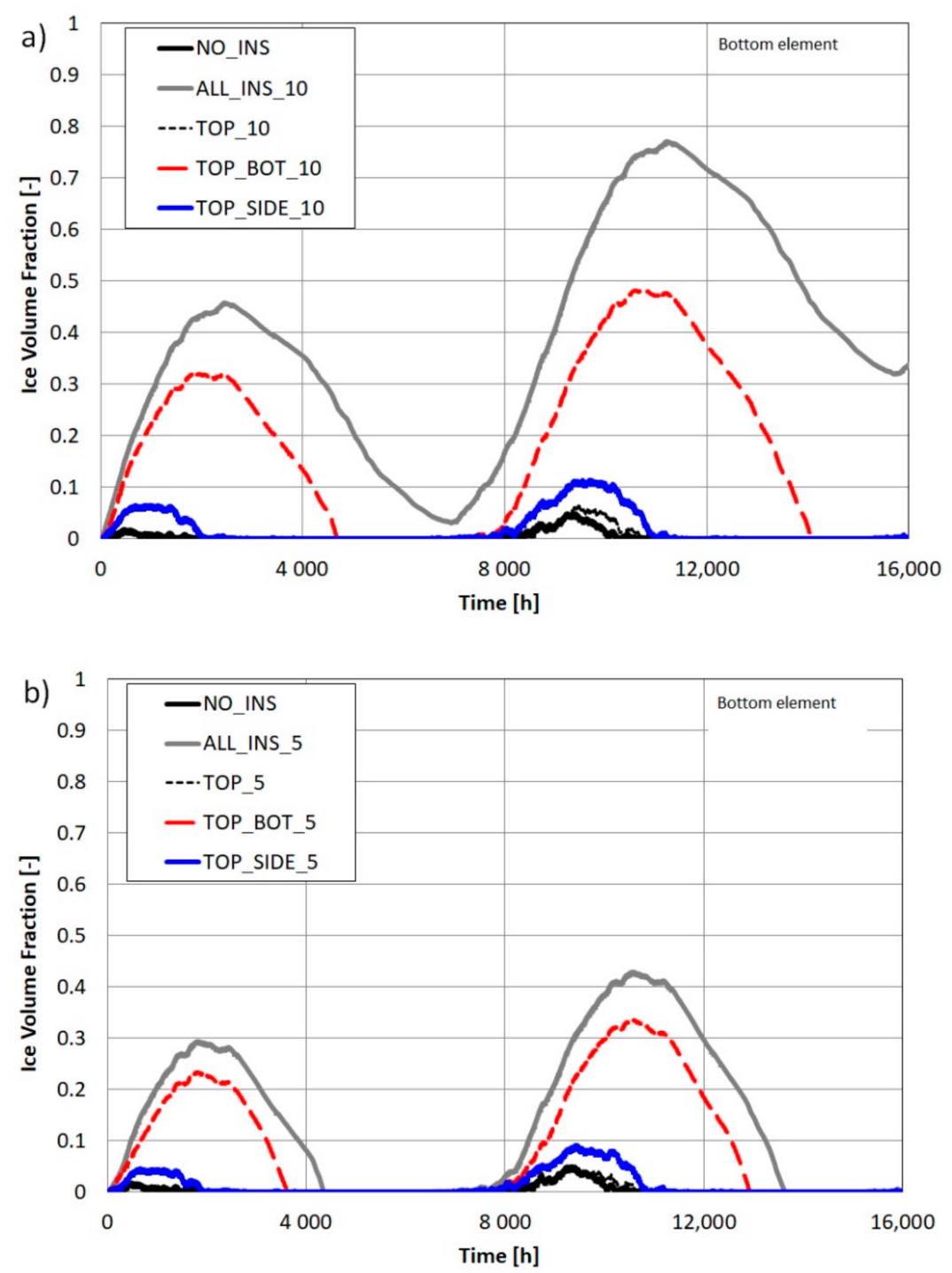

Figure 10. Ice volume fraction of the bottom element of the IT: (a) 10-cm cases; (b) 5-cm cases.

On the other hand, as an outcome of Figure 8, in the TOP_5 case, only around 50\% of the total storage volume was frozen during the reference heating season; this might mean that even if this solution shows the lowest primary energy consumption, an optimized solution might be found.

The first consideration involves the total storage volume, which seems to be too large as compared to the maximum amount of ice formed (Figure 8). For this reason, two different volumes were considered, which are 76\% and 64\% (TOP_5_CYL_1 and TOP_5_CYL_2, respectively) of the reference one (see Table 1).

Furthermore, since all walls, with the exception of the top surface, are not insulated, there is the possibility to mitigate the heat losses considering a different shape of the IT. For this reason, a truncated cone storage, with the top surface diameter equal to $6 \mathrm{~m}$ and the bottom one equal to $2 \mathrm{~m}$, was designed. This storage has a volume $24 \%$ lower than the TOP_5 case, which is the same as the TOP_5_CYL_1. In this way, it is possible to analyze the effect of storage shape on the I-TES performance, keeping its volume constant.

The results of the simulations are plotted in Figure 11, where the primary energy consumptions of the new solutions are summarized. As one can see, the former TOP_5 case exhibits the best performance as compared with the other proposed solutions, which present smaller volumes. 


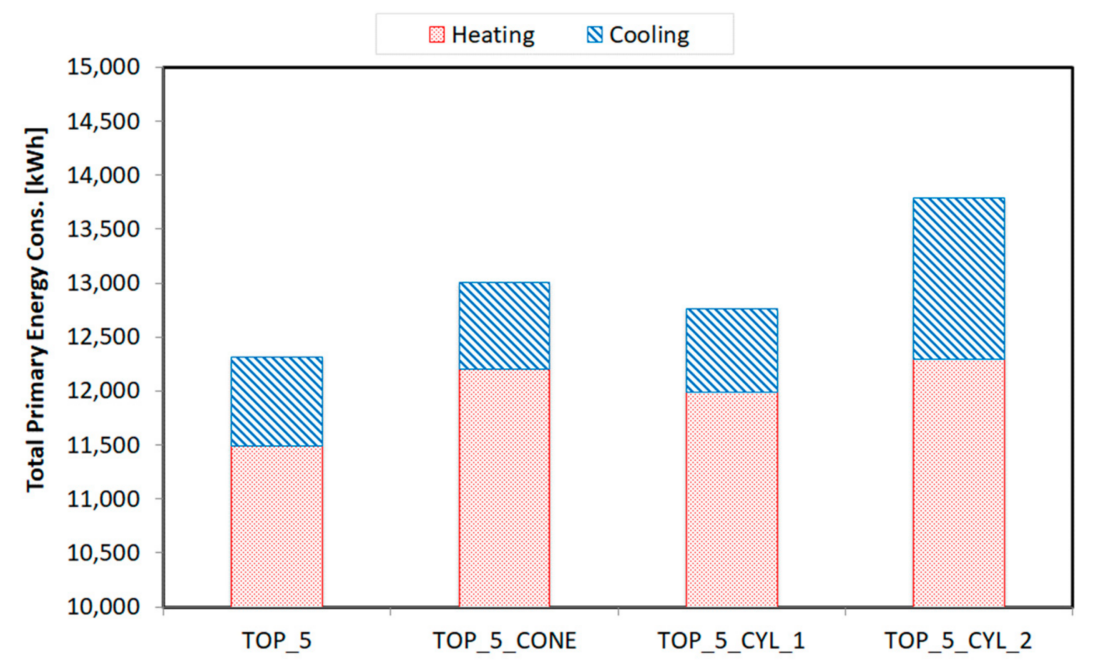

Figure 11. Primary energy consumption for the alternative developed solutions.

This might be explained considering the energetic analysis of the IT proposed in Figure 12. As already found for the other base cases, the energy stored in the IT and the cooling contributions of the different solutions are almost the same for all the new solutions. What is slightly different is the capacity of the storage to "dissipate" the energy (ice) stored during the heating season. The TOP_5 solution dissipates the largest amount of cold energy without penalizing the cooling season.

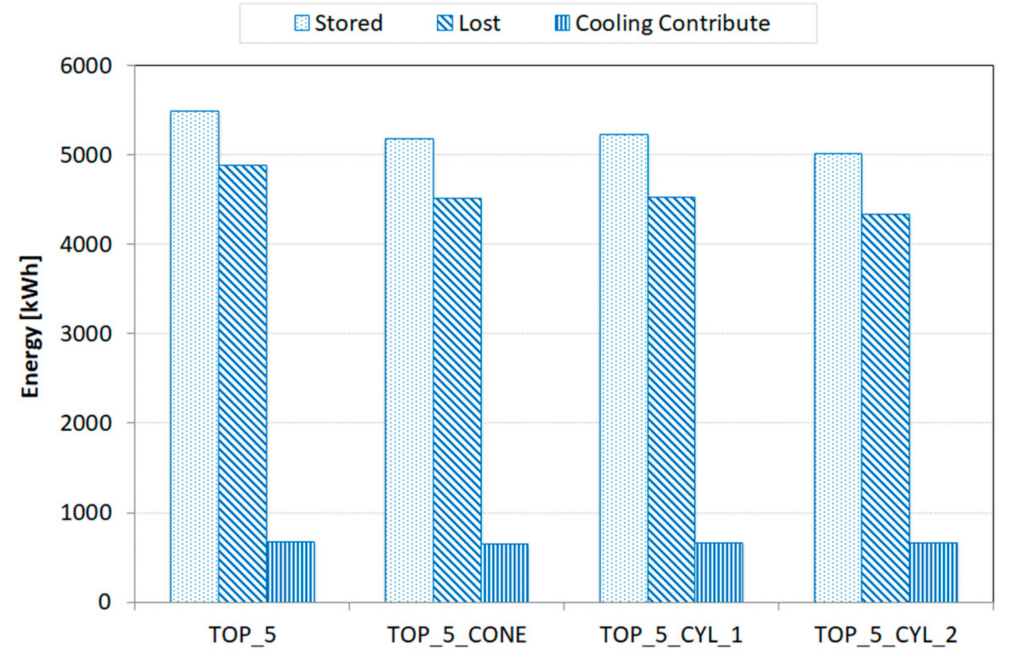

Figure 12. Energy analysis of the IT.

This information can be found also in Figures 13-15; they compare the ice volume fraction of the whole storage and of the $3 \mathrm{rd}$ and of the bottom elements, respectively. The overall ice volume fraction reported in Figure 13 shows the greater ability of the solutions with smaller volumes to freeze the water contained in the IT during the winter. In particular, the smaller the IT volume, the higher the amount of water frozen, being around $45 \%, 65 \%$ and $75 \%$ when the volume passes from 58.8 (TOP_5) to 44.6 (TOP_5_CYL_1) and to $37.7 \mathrm{~m}^{3}$ (TOP_5_CYL_2).

When the shape of the IT is changed, the amount of energy lost decreases because the heat transfer area proportionally decreases; in fact, the TOP_5_CONE shows a greater ice volume fraction as compared to TOP_5_CYL_1, which has the same IT volume.

Figure 14 shows the ice formed in the 3rd element; it is worth underlining that the volume could not be reduced anymore because the ice formed in the case of TOP_CYL_2 is more than $95 \%$. 


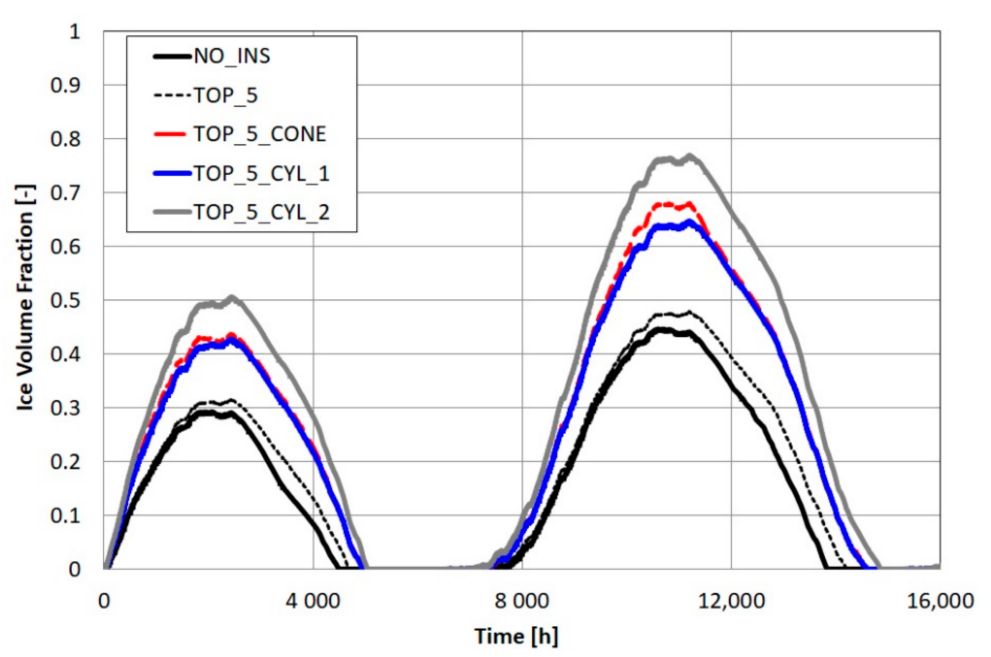

Figure 13. Ice volume fraction of the IT.

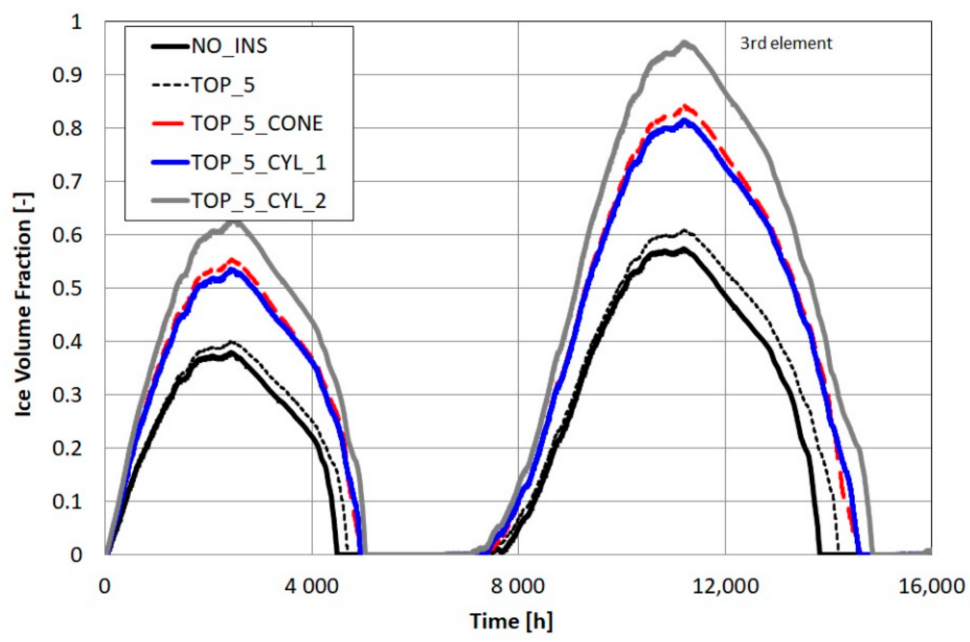

Figure 14. Ice volume fraction of the 3rd element of the IT.

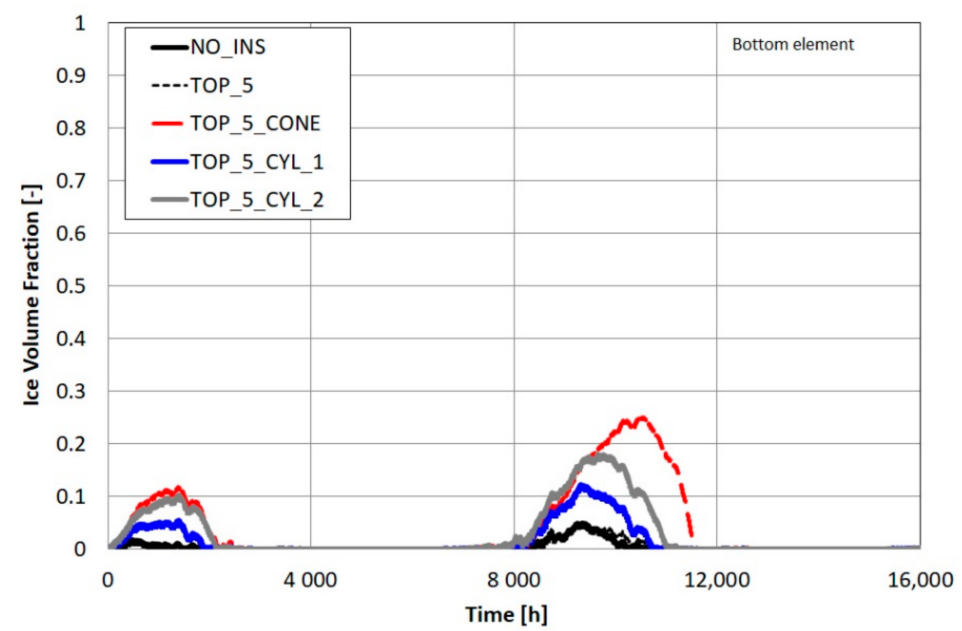

Figure 15. Ice volume fraction of the bottom element of the IT.

Considering Figure 15, the bottom element becomes most penalized by the heat gain, even if it permits dissipating the largest amount of the energy stored in the ice tank, ensuring a sustainable energy equilibrium of the IT and of the system itself. Nevertheless, there is not a deep difference 
between the different solutions, but those that present a higher frozen volume in the bottom layer are also those that exhibit higher primary energy consumptions.

\section{Conclusions}

This paper shows the results relative to the implementation of an I-TES integrated with an HP for annual air conditioning. Many IT cases with different insulation layer thicknesses and shapes were compared in order to analyze their effects on the primary energy consumption of the system. It was found that the annual performance depends on the equilibrium between cold energy stored into the IT during the winter and its capacity to dissipate this energy being able to satisfy the whole cooling load during the summer. This equilibrium controls the performance of the system and depends on the particular case (climate, building, system, etc.).

In the present case study, a $5 \mathrm{~cm}$ thick layer positioned on the top wall of the IT was found to be the optimum solution as compared to the other insulation cases, at a constant storage volume of $58.8 \mathrm{~m}^{3}$. This optimum solution was then compared against others, which had the same insulation layout but with different volumes and shape of the IT. Again, it was found that the minimum primary energy consumption was obtained by the TOP_5 case. In particular, the ability of the IT to dissipate the energy stored to the soil is fundamental to balance the heating and the cooling loads. An economic analysis could be useful to assess which solution could be the most advantageous.

Author Contributions: Conceptualization, S.M. and M.N.; methodology, S.M. and M.N.; software, S.M.; validation, S.M. and M.N.; writing_-original draft preparation, S.M.; writing-review and editing, M.N. All authors have read and agreed to the published version of the manuscript.

Funding: This work was founded by the Italian Ministry of Education, University and Research (MIUR) through PRIN 2017 FlexHeat 2017KAAECT project.

Acknowledgments: The contribution of Luca Fornari is gratefully acknowledged.

Conflicts of Interest: The authors declare no conflict of interest.

\section{Abbreviations}

$\begin{array}{ll}\text { Cfb } & \text { Koppen climate classification of a temperate and humid in all-seasons climate } \\ \text { with a hot summer-the hottest month has a mean temperature lower than } 22{ }^{\circ} \mathrm{C} . \\ \text { GHE } & \text { Ground heat exchanger } \\ \text { GSHP } & \text { Ground source heat pump } \\ \text { HP } & \text { Heat pump } \\ \text { HVAC } & \text { Heating, ventilation, air conditioning } \\ \text { ID } & \text { Internal diameter, mm } \\ \text { I-TES } & \text { Ice thermal energy storage } \\ \text { IT } & \text { Ice tank } \\ \text { PCM } & \text { Phase change material } \\ \text { PE } & \text { Polyethylene } \\ \text { PES } & \text { Primary energy saving } \\ \text { PVT } & \text { Photovoltaic/thermal } \\ \text { TES } & \text { Thermal energy storage } \\ \text { UTES } & \text { Underground thermal energy storage }\end{array}$

\section{References}

1. Dincer, I.; Rosen, M.A. Thermal Energy Storage: Systems and Applications; John Wiley \& Sons Ltd.: Chichester, UK, 2011; ISBN 978-0-470-74706-3.

2. Dincer, I.; Calin, Z. Sustainable Energy Systems and Applications; Springer: New York, NY, USA, 2011; ISBN 978-0-387-95860-6.

3. Lanahan, M.; Tabares-Velasco, P.C. Seasonal thermal-energy storage: A critical review on BTES systems, modeling, and system design for higher system efficiency. Energies 2017, 10, 743. [CrossRef] 
4. Guo, M.; Diao, N.; Man, Y.; Fang, Z. Research and development of the hybrid ground-coupled heat pump technology in China. Renew. Energy 2016, 87, 1033-1044. [CrossRef]

5. Gao, O.; Li, M.; Yu, M. Review of development from GSHP to UTES in China and other countries. Renew. Sustain. Energy Rev. 2009, 13, 1383-1394. [CrossRef]

6. Zhu, N.; Hu, P.; Xu, L.; Jiang, Z.; Lei, F. Recent research and applications of ground source heat pump integrated with thermal energy storage systems: A review. Appl. Therm. Eng. 2014, 71, 142-151. [CrossRef]

7. Luo, Y.; Yan, T.; Yu, J. Integrated analytical modeling of transient heat transfer inside and outside U-tube ground heat exchanger: A new angle from composite-medium method. Int. J. Heat Mass Transf. 2020, 162, 120373. [CrossRef]

8. Hałaj, E.; Pajak, L.; Papiernik, B. Finite element modeling of geothermal source of heat pump in long-term operation. Energies 2020, 16, 1341. [CrossRef]

9. Lazzarin, R.; Noro, M. Photovoltaic/Thermal (PV/T)/ground dual source heat pump: Optimum energy and economic sizing based on performance analysis. Energy Build. 2020, 211, 109800. [CrossRef]

10. Spitler, J.D.; Gehlin, S. Measured performance of a mixed-use commercial-building ground source heat pump system in Sweden. Energies 2019, 12, 2020. [CrossRef]

11. Lazzarin, R.; Noro, M. Lessons learned from long term monitoring of a multisource heat pump system. Energy Build. 2018, 174, 335-346. [CrossRef]

12. Noro, M.; Lazzarin, R.; D'Ascanio, A. Energy and economic analysis of an underground water source heat pump system for a historical valuable building. Energy Procedia 2017, 133, 171-182. [CrossRef]

13. Sanner, B.; Karytsas, C.; Mendrinos, D. Current status of ground source heat pumps and underground thermal energy storage in Europe. Geothermics 2003, 32, 579-588. [CrossRef]

14. Yang, W.; Zhou, J.; Xu, W. Current status of ground-source heat pumps in China. Energy Policy 2010, 38, 323-332. [CrossRef]

15. Zhai, X.Q.; Qu, M.; Yu, X.; Yang, Y.; Wang, R.Z. A review for the applications and integrated approaches of ground-coupled heat pump systems. Renew. Sustain. Energy Rev. 2011, 15, 3133-3140. [CrossRef]

16. Lazzarin, R.; Noro, M.; Righetti, G.; Mancin, S. Application of Hybrid PCM Thermal Energy Storages with and without Al Foams in Solar Heating/Cooling and Ground Source Absorption Heat Pump Plant: An Energy and Economic Analysis. Appl. Sci. 2019, 9, 1007. [CrossRef]

17. Righetti, G.; Lazzarin, R.; Noro, M.; Mancin, S. Phase Change Materials embedded in porous matrices for hybrid thermal energy storages: Experimental results and modelling. Int. J. Refrig. 2019, 106, 266-277. [CrossRef]

18. Zhang, H.F.; Ge, X.S.; Ye, H. Modeling of a space heating and cooling system with seasonal energy storage. Energy 2007, 32, 51-58. [CrossRef]

19. Rohde, D.; Andresen, T.; Nord, N. Analysis of an integrated heating and cooling system for a building complex with focus on long-term thermal storage. Appl. Therm. Eng. 2018, 145, 791-803. [CrossRef]

20. D'Ingeo, A. GAHP e GIS: Pompe di calore ad assorbimento e accumuli stagionali interrati di ghiaccio per la climatizzazione annuale a basso impatto ambientale. (GAHP and GIS: Absorption heat pumps and ground ice seasonal storages for low environmental impact annual climatization. In Italian). In Proceedings of the AiCARR Congress "Energie rinnovabili: Tecniche e potenzialità" ("Renewable energies: Techniques and potentials"), Padova, Italy, 21 June 2007.

21. Carbonell, D.; Philippen, D.; Haller, M.Y.; Brunold, S. Modeling of an ice storage buried in the ground for solar heating applications. Validations with one year of monitored data from a pilot plant. Sol. Energy 2016, 125, 398-414. [CrossRef]

22. Carbonell, D.; Philippen, D.; Granzotto, M.; Haller, M.Y.; Frank, E. Simulation of combined solar thermal, heat pump, ice storage and waste water heat recovery systems. Design criteria and parametric studies. In Proceedings of the EuroSun, International Solar Energy Society (ISES), Aix les Bains, France, 16-19 September 2014.

23. Philippen, D.; Carbonell, D.; Granzotto, M.; Zenhäusern, D.; Haller, M.Y.; Brunold, S. High-Ice-System Development for High Solar Thermal Gains with Ice Storage and Heat Pump; Institut für Solartechnik SPF for Swiss Federal Office of Energy (SFOE), Research Programme Solar Heat and Heat Storage, CH-3003 Bern; SFOE: Pulverstrasse, Switzerland, 2015. 
24. Klein, S.A. TRNSYS 17: A Transient System Simulation Program, Solar Energy Laboratory; University of Wisconsin: Madison, WI, USA, 2010. Available online: http://sel.me.wisc.edu/trnsys (accessed on 8 October 2020).

25. Jonas, D.; Theis, D.; Meiers, J.; Frey, G. Model-based analysis of solar thermal and heat pump systems using TRNSYS. In Proceedings of the ISES Solar World Congress 2017-IEA SHC International Conference on Solar Heating and Cooling for Buildings and Industry 2017, Abu Dhabi, UAE, 29 October-2 November 2017; pp. 2216-2227.

Publisher's Note: MDPI stays neutral with regard to jurisdictional claims in published maps and institutional affiliations.

(C) 2020 by the authors. Licensee MDPI, Basel, Switzerland. This article is an open access article distributed under the terms and conditions of the Creative Commons Attribution (CC BY) license (http://creativecommons.org/licenses/by/4.0/). 